\section{Bad times force the Swiss to reduce spending plans}

Basel. The Swiss federal government has for the second year running reneged on a budgetary promise to researchers, leading to cuts so severe that some departments may have to close. The reductions are part of the government's attempt to reduce an annual deficit as high as SFr5 billion (US\$3.5 billion).

The Swiss National Science Foundation (NSF), which awards grants to university scientists, was told recently that the increase of 9.5 per cent it was promised in 1991 has been cut in half as a result of a decision by the Swiss parliament to trim federal spending by 10 per cent. The foundation is still reeling from a decision last year by parliament to reduce by half its budget for a new strategic research programme.

Universities will fare even worse in the retrenchment. Although the federal government provides only 16 per cent of their budget (individual cantons provide the rest), universities were promised an increase of 23 per cent in 1993 after a 1991 report showed that the government had fallen behind on its commitment to university research. But given its current problems, the government this year will offer an increase of only 3 per cent ( see chart), a figure that barely matches the rate of inflation.

This decision will force universities to eliminate posts, according to Nivardo Ischi, general secretary of the body that represents Swiss university administrators. He estimates that career opportunities for young researchers will shrink by half between 1992 and 1995.

Cantons are also feeling the pinch. For example, the Basel government has asked its university to propose ways to reduce spending by 14 per cent, and the administration has suggested closing its teaching programmes for preclinical medical students and also several departments. The University of Bern must save SFr8 million by 1996 , and is expected to lose half a dozen professors from a 80-member science faculty.

Reduced federal spending also affects independent research institutes such as the Swiss Institute for Experimental Cancer Research in Lausanne. The institute will get SFr1 million less this year than the SFr6.6 million it expected from federal sources, forcing it to dip into its capital to cover operating costs. "We fear that good researchers may leave us because they feel the institute has no future", says its director, Bernhard

\section{Promises, promises}

Government spending on university research

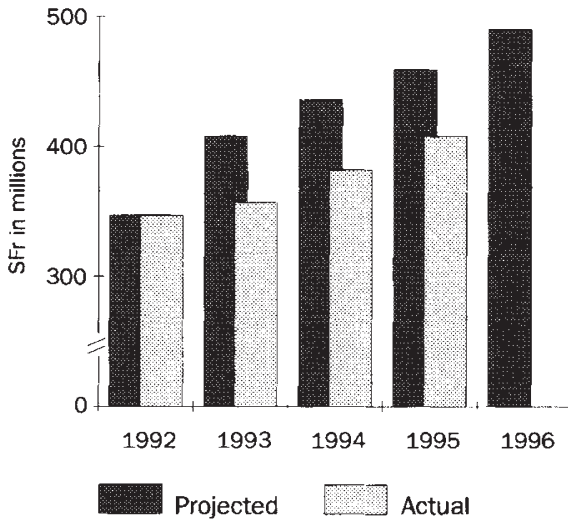

Hirt, who has been unable to recruit replacements for a retrovirus research team that left last year.

As the situation in universities worsens, the number of researchers asking the Swiss NSF for grants increased by 15 per cent between 1990 and 1991. In response, the NSF plans to distribute the reductions evenly across all areas, postponing or cancelling many new projects.

However, general secretary Peter Fricker sees a silver lining in the latest cloud. "I don't fear a brain drain", he says, "because the situation abroad is certainly no better."

Oliver Klaffke

\title{
Germany asked to increase spending on universities
}

Munich. Germany's influential science council, the Wissenschaftsrat, wants the government to increase spending on university research and on institutions in the eastern states.

The Deutsches Forschungsgemeinschaft (DFG), the largest sponsor of university research, for the first time is rejecting a majority of grant applications because its budget has not kept pace with increased demand from a growing scientific community. Germany remains among the leading sponsors of research and development in the world, with spending as a percentage of gross domestic product (GDP) rising 0.4 points to 2.81 per cent during the $1980 \mathrm{~s}$. But the science council, in a recent report, argues that universities are not getting their fair share.

Total spending on university-based research has fallen since 1975 from 1.32 per cent to 1.12 per cent of GDP. Germany's recent economic boom, combined with a 45-year-old law guaranteeing higher education for all high school graduates, has contributed to a near doubling of the annual number of university graduates during that period, from 841,000 to $1,582,000$. That growth has led to an increased demand for research funds (more than 10,000 applications in 1991).

The success rate has fallen steadily for the past two decades, from more than 70 per cent in the 1970s to 60 per cent in 1985 and to 43.3 per cent last autumn. For the first time, the DFG finds itself unable to fund even projects assigned top grades. This is unacceptable, says the science council, which believes that the DFG, to function properly, should fund at least half of the applications.

An agreement in 1990 between publicly funded research organizations and the federal and regional governments pegged the growth in spending to five per cent a year for five years. This 'five-times-five' agreement ran into trouble last year (see Nature 357, $182 ; 1992$ ) when wage settlements of 5.4 per cent were granted. Despite that, Wilhelm Krull of the science council would like the governments to extend the agreement to the end of the century so that grant-giving bodies can plan a long-range strategy. In the face of a faltering economy, it argues, support for research should be maintained to ensure that the country holds its competitive edge.

The financial strain on research funding has been increased since reunification in October 1990, when the DFG was told to make research in eastern universities on a par with western levels. In 1991 it was given DM90 million (US\$55 million) for that purpose, but the amount has been insufficient. The DFG has long argued that universities in eastern Germany are so old and badly maintained that they cannot offer the most fundamental of facilities for modern research. "We can give a university a beautiful new centrifuge or Coulter counter", says Christoph Schneider of the DFG, "but then we find that the lab floor, with unrepaired holes giving a view to the storey below, simply cannot bear the weight".

The science council believes that research facilities must be rebuilt before standards can be raised, but it does not want the DFG's grant money to be diverted from research. Instead, it says, the federal and regional governments should meet their joint responsibility for rebuilding the infrastructure.

The council is composed of representatives from federal and regional governments, including those from finance and planning departments, as well as scientists. The new report must now pass through several levels of political assessment. Although the council has a good record of success with its recommendations, that may be more difficult this time around as Germany tries to revive a troubled economy. Alison Abbott 